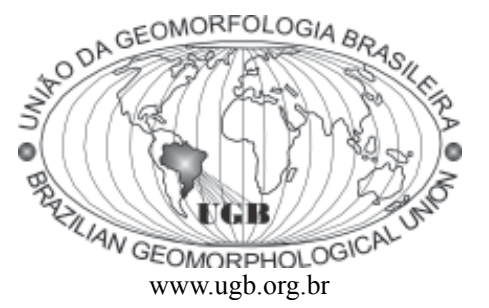

\title{
CARACTERIZAÇÃO DO RELEVO DA REGIÃO DE MANAUS, AMAZÔNIA CENTRAL
}

Roseane Ribeiro Sarges

Programa de Pós-graduação em Geoquímica e Geotectônica, Instituto de Geociências, Universidade de São Paulo, rua do Lago, 562, São Paulo, Brasil - CEP 05508-080 - e-mail: roseanesarges@hotmail.com;

Telma Mendes da Silva

Departamento de Geografia, Instituto de Geociências, Universidade Federal do Rio de Janeiro, Ilha do Fundão, Rio de Janeiro, Brasil - CEP 21941-909 - e-mail: telmendes@globo.com;

\author{
Claudio Riccomini \\ Bolsista de produtividade em pesquisa do CNPq - Departamento de Geologia Sedimentar e Ambiental, Instituto de \\ Geociências, Universidade de São Paulo, Rua do Lago, 562, São Paulo, Brasil - CEP 05508-080 - e-mail: riccomin@usp.br.
}

\begin{abstract}
Resumo
O relevo da região de Manaus, nordeste do estado do Amazonas, foi caracterizado por meio de análise da distribuição das feições geomórficas, definição dos compartimentos do relevo e identificação de elementos morfoestruturais. Os resultados indicaram que movimentações tectônicas foram responsáveis por duas fases de reorganização da rede de drenagem, que condicionaram o modelado da região e promoveram duas significativas reorganizações da rede de drenagem: a primeira, resultante da inversão do fluxo do rio Amazonas e uma segunda, que foi responsável pela captura e alteração do fluxo de canais de drenagem do interflúvio rio Negro - rio Branquinho, ocasionando a formação de um novo compartimento topográfico $(\Delta \mathrm{h}=75 \mathrm{~m})$. Os processos geomorfogenéticos propiciaram o aplainamento dos topos dos interflúvios em um estágio inicial, ação erosiva que levou a formação das superfícies geomorfológicas S1 e S2, mais antigas e associadas aos eventos de lateritização da área, e atualmente conduz a pediplanação da área, correlacionada à geração da superfície S3.
\end{abstract}

Palavras-chave: Relevo, geomorfometria, evolução da paisagem, Amazônia.

\begin{abstract}
The relief characterization of the Manaus region, in northeastern of the state of Amazonas, was based on the analysis of the distribution of the geomorphic features, definition of the topographics domains and identification of the morphostructural elements of the landscape. The shaping the landscape was controlled by two tectonic events, each of which caused significant reorganization of the existing drainage network. The first event resulted from the inversion of the flow direction of Amazonas river, whereas the second was responsible for the capture and flow alteration of the drainage channels of the Negro - Branquinho divides, causing the formation of a new topographical domains $(\Delta \mathrm{h}=75 \mathrm{~m})$. The geomorphogenetic processes propitiated the leveling of the tops of the watershed in the initial stage. This erosional action lead initially to the formation of the old geomorphological surfaces S1 and S2, associated with lateritization events, and to present day pediplanation of the region (correlated with S3 surface).
\end{abstract}

Keywords: Relief, geomorphometry, landscape evolution, Amazonia. 


\section{Introdução}

A Amazônia passou por importantes alterações na paisagem durante o Cenozóico. A atuação integrada de movimentações tectônicas, responsáveis por soerguimentos e abatimentos em vários terrenos amazônicos e por rearranjos na rede de drenagem, e variações climáticas-ambientais, atuantes desde o Paleógeno (Sternberg, 1950; Meis, 1971; Tricart, 1977; Costa, et al., 1978; Cunha, 1990; Hoorn et al. 1995, Horbe et al. 2001, Costa 2002, Franzinelli; Igreja, 2002; Bezerra, 2003; Mapes et al., 2006; Almeida-Filho; Miranda, 2007) ativou os processos geomorfogenéticos na região amazônica.

Neste trabalho, buscou-se avaliar os efeitos destes mecanismos na paisagem, a partir da quantificação de elementos geomórficos, utilizando os modelos digitais de elevação (DEM's) disponibilizados pelo USGS (2003), que traz importantes informações sobre as características de relevo desta região. A quantificação de elementos do relevo, técnica utilizada desde meados do século passado (Horton, 1932; Strahler, 1952; Howard, 1967), vem sendo aplicada em estudos neotectônicos e de compartimentação de relevo (Meis et al., 1982; Golts; Rosenthal, 1993; Jianjun et al., 1997; Hiruma; Riccomini, 1999). No entanto, a resposta dada pelos estudos morfométricos pode ir além da delimitação e quantificação de feições geomorfológicas, auxiliando na interpretação e subsidiando a compreensão dos eventos geomorfológicos que afetaram uma dada região. Desta forma, o presente estudo busca investigar as características do relevo, bem como interpretar os processos erosivos e tectônicos envolvidos na elaboração da paisagem da região de Manaus.

\section{Área de Estudo}

A singular paisagem da porção nordeste do estado do Amazonas é caracterizada por conjuntos topográficos desenvolvidos sobre rochas siliciclásticas da Bacia do Amazonas, isolados pelos rios Negro, Uatumã e Jatapu (Fig. 1A e B). O conjunto topográfico $\mathrm{I}$, onde está inserida a área de estudo (Figs. 1A, B e C), apresenta relevo tabuliforme constituído por interflúvios tabulares com diferentes graus de dissecação. O conjunto topográfico I foi modelado sobre rochas da borda norte da Bacia do Amazonas (Fig. 1C). Na porção setentrional deste conjunto, ocorrem arenitos, folhelhos e siltitos pertencentes ao Grupo Trombetas, depositados em ambiente marinho a glácio-marinhos no intervalo Siluro-devoniano (Cunha et al., 1994). Os limites na porção sul são estabelecidos pelos arenitos, siltitos e argilitos fluviais a flúvio-lacustres cretáceos (Caputo et al., 1972; Cunha et al., 1994; Nogueira et al., 1999), pertencentes à Formação Alter do Chão, unidade predominante da área, arenitos ferruginosos da Formação Novo Remanso (Rozo et al., 2005) e sedimentos flúvio-lacustres quaternários (Latrubesse; Franzinelli, 2002, Nogueira et al., 2006). O desní- vel topográfico entre o limite da borda norte e o limite sul, está representado no perfil topográfico $\mathrm{ABC}$ (Fig. 1D). O trecho $\mathrm{AB}$, que abrange o contato entre a borda norte da Bacia do Amazonas e o embasamento Proterozóico, apresenta variação de altitude de $203 \mathrm{~m}$ para $44 \mathrm{~m}$ em uma distância de $9 \mathrm{~km}$. No segmento $\mathrm{BC}$, que representa os desníveis altimétricos do conjunto topográfico 1 , a altitude decresce gradualmente de $203 \mathrm{~m}$ para $14 \mathrm{~m}$ em $204 \mathrm{~km}$ de distância, em direção ao rio Amazonas. A ocorrência do acentuado desnível topográfico no segmento $\mathrm{AB}$ tem relação direta com a preservação dos interflúvios tabulares nesta porção setentrional, enquanto a sul tendem a apresentar formas tabulares com maior dissecação nas proximidades das margens dos rios Amazonas, Negro, Cuieiras, Preto da Eva e Uatumã, que correspondem aos rios de maior porte da área (Fig. 1A).

\section{Material e Métodos}

Estudos geomorfométricos no estado do Amazonas sempre foram preteridos devido à precária cobertura topográfica da região, onde apenas a porção sul da área urbana da cidade de Manaus possui cobertura topográfica que possibilita estudos geomorfométricos que subsidiou a elaboração da Carta de Declividades de Manaus (Bento; Frota, 1999). Neste contexto, os MDE's disponibilizados pelo USGS (2003), resultantes da missão SRTM (Hennig et al., 2001), com as devidas correções necessárias (Barros et al., 2004; Santos et al., 2005), constituem uma solução alternativa para os históricos problemas de cartografia topográfica da região amazônica. Análises cartográficas realizadas por Santos et al. (2005) confirmam que os MDE's SRTM apresentam PEC (Padrão de Exatidão Cartográfico) de categoria A, definido pelas normas brasileiras de cartografia, com erro médio quadrático de 11,066 m e 97,75 \% dos pontos abaixo da tolerância vertical em escala de 1:100.000. Sendo assim, a partir destes MDE's é possível a aquisição de variáveis geomorfométricas (Valeriano, 2004; Valeriano et al., 2006; Grohmann et al., 2007), viabilizando os estudos geomorfométricos na região de Manaus. A caracterização morfológica da região em estudo, que possui extensão de $7.295 \mathrm{~km}^{2}$ e perímetro de $366 \mathrm{~km}$ e está inserida entre as coordenadas geográficas $2^{\circ} 30^{\prime} 00^{\prime \prime} \mathrm{S}$ e $60^{\circ} 30^{\prime} 00^{\prime \prime} \mathrm{W}$ a $3^{\circ} 15^{\prime} 00^{\prime \prime} \mathrm{S}$ e $59^{\circ} 30^{\prime} 00^{\prime \prime} \mathrm{W}$, foi realizada por meio da análise de parâmetros geomorfométricos adquiridos dos MDE's SRTM (USGS, 2003). Aos MDE's foram adicionados, ainda, os lagos e os canais de drenagens, digitalizados a partir de cartas topográficas na escala 1:100.000. O reconhecimento das feições de relevo da área constou assim de diferentes etapas de trabalho: a) uma primeira caracterização foi fundamentada na análise da distribuição e nos contornos das formas na definição dos macro-compartimentos do relevo da área a partir da elaboração do mapa hipsométrico e do reconhecimento de diferentes faixas altimétricas (Strahler, 1952), além dos valores de declividades das encostas; b) 
compartimentação topográfica a partir da aplicação da base metodológica fundamentada no cálculo do índice de desnivelamento altimétrico de bacias de drenagem formadoras dos sistemas fluviais (Meis et al., 1982; Silva, 2002); c) e na identificação de feições morfotectônicas, relacionadas a aspectos morfográficos e morfogenéticos, utilizando análises de superfícies de base, declividades, densidade de lineamentos e densidade de drenagem (Horton, 1945; Golts; Rosenthal, 1993; Hiruma; Riccomini, 1999). A caracterização morfológica foi complementada por análises do arranjo da rede de drenagem e classificação dos padrões de drenagem, seguindo proposta de Howard (1967).

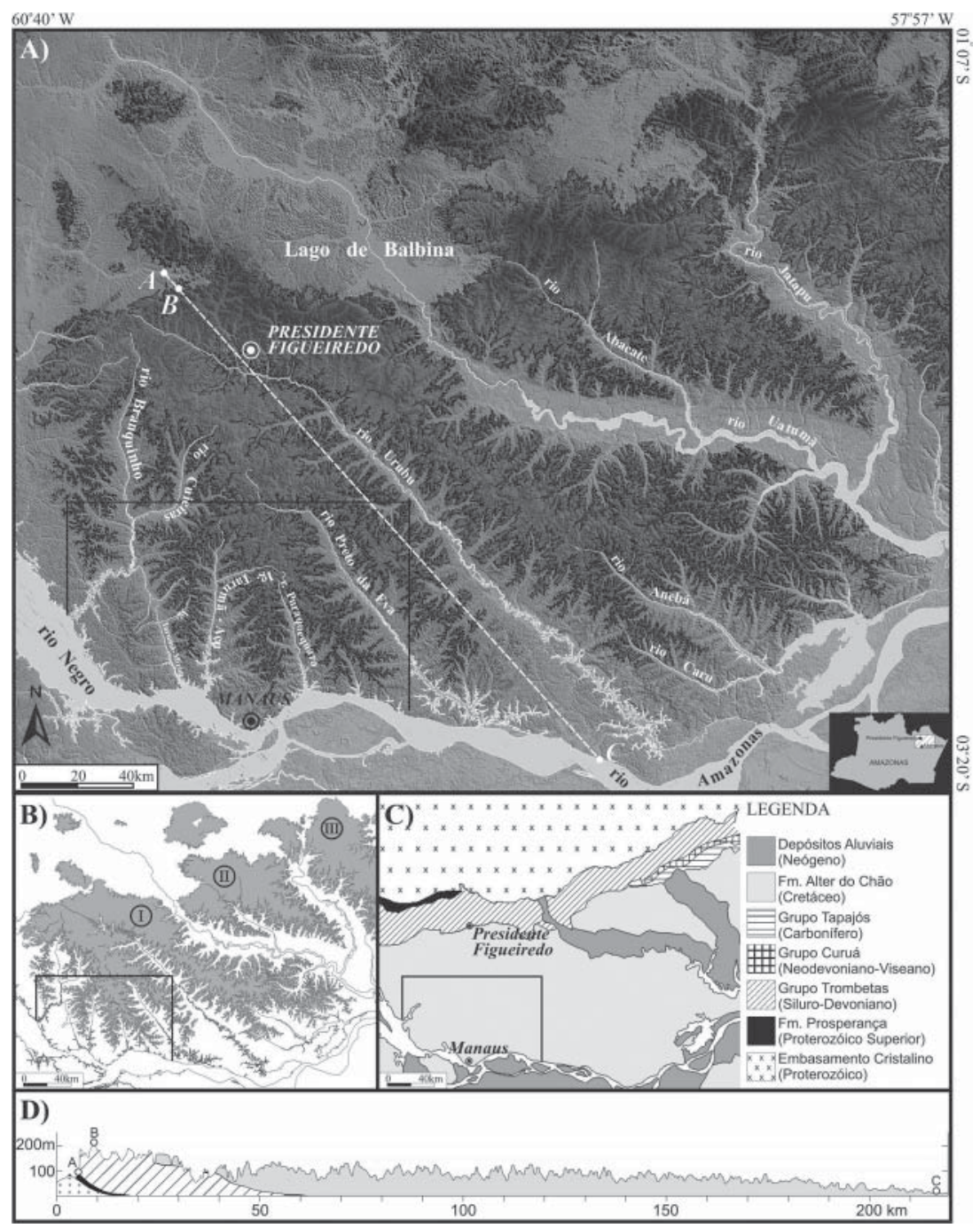

Figura 1 - Contextualização da área de estudo na região nordeste do estado do Amazonas. A) Distribuição dos divisores topográficos, desenvolvidos sobre as rochas sedimentares da Bacia do Amazonas. A área de estudo, delimitada pela linha preta situada entre os rios Cuieiras e Preto da Eva, está desenvolvida sobre o dominio geomorfológico Planalto Dissecado Rio Trombetas - Rio Negro (Nascimento et al., 1976). B) Em destaque, os conjuntos topográficos (I, II e III), com limite das curvas de nivel em 90m, individualizados pelos rios Negro, Uatumã e Jatapu. C) Distribuição das unidades geológicas da região (adaptado de Nogueira; Sarges, 2001; Rosseti et al., 2005; Nogueira et al., 2006), sobre as quais estão desenvolvidos os conjuntos topográficos, com representação do limite da área de estudo pela linha preta. D) Perfil geológicotopográfico $A B C$, com direção azimutal de 140, onde estão contidos os máximos e mínimos altimétricos, respectivamente pontos $B$ e $C$, do conjunto topográfico I.

\section{Características do Relevo da Região de Manaus}

A distribuição das formas de relevo em função da variação altimétrica permitiu a definição de cinco faixas hipsométricas (Fig. 2A), que mostram a relação entre a distribuição e organização espacial das feições geomórficas da área. Em porções da área com altitudes inferiores a $25 \mathrm{~m}$ que abrangem os vales dos rios Amazonas, Negro, Cuieiras, Tarumã Açu, Tarumã Mirim, Puraquequara e Preto da Eva, ocorrem feições morfológicas de barras de canais e planícies de inundação de grandes extensões. $\mathrm{O}$ intervalo altimétrico entre 25 e $65 \mathrm{~m}$, que coincidem com vales e planícies de tributários dos rios Negro e Amazonas, é constituído por terraços fluviais e terraços erosivos. A faixa altimétrica entre 65 e 90m abrange as vertentes dos interflúvios tabulares estreitos e com elevado grau de dissecação. O intervalo altimétrico entre 90 e $115 \mathrm{~m}$ é representativo dos divisores de drenagens ramificados e alongados na direção NW-SE e N-S, com ampla distribuição em área. A faixa altimétrica maior que $115 \mathrm{~m}$ engloba os topos planos dos divisores tabulares, com distribuição restrita na porção centro-norte da área. Em relação à declividade da região, a área apresenta baixos valores de declividades, com gradiente máximo de $18^{\circ}$ (Fig. 2B). As maiores declividades, entre $12^{\circ}$ e $18^{\circ}$ (representadas pela cor preta na figura 5.2B), ocorrem nas bordas dos terraços fluviais e nas vertentes dos interflúvios alongados de topos planos. As 
vertentes dos interflúvios intensamente dissecados apresentam declives com ângulo entre $6^{\circ}$ e $11^{\circ}$, enquanto os segmentos com menores declividades $\left(0^{\circ}-5^{\circ}\right)$, representadas pela cor branca, correspondem aos fundos de vales, nas planícies e nos topos dos interflúvios tabulares. Os desníveis topográficos da região de Manaus refletem o elevado grau de incisão fluvial e entalhamento erosivo das vertentes, mecanismos estes que devem estar associados às variações tectônicas (Meis et al., 1982; Silva et al., 1995), uma vez que a litologia da área é constituída essencialmente por rochas sedimentares, geralmente friáveis em função do intenso intemperismo atuante na região. Na compartimentação topográfica foram reconhecidas três classes de desnivelamento altimétrico, com interpretação do significado geomorfológico
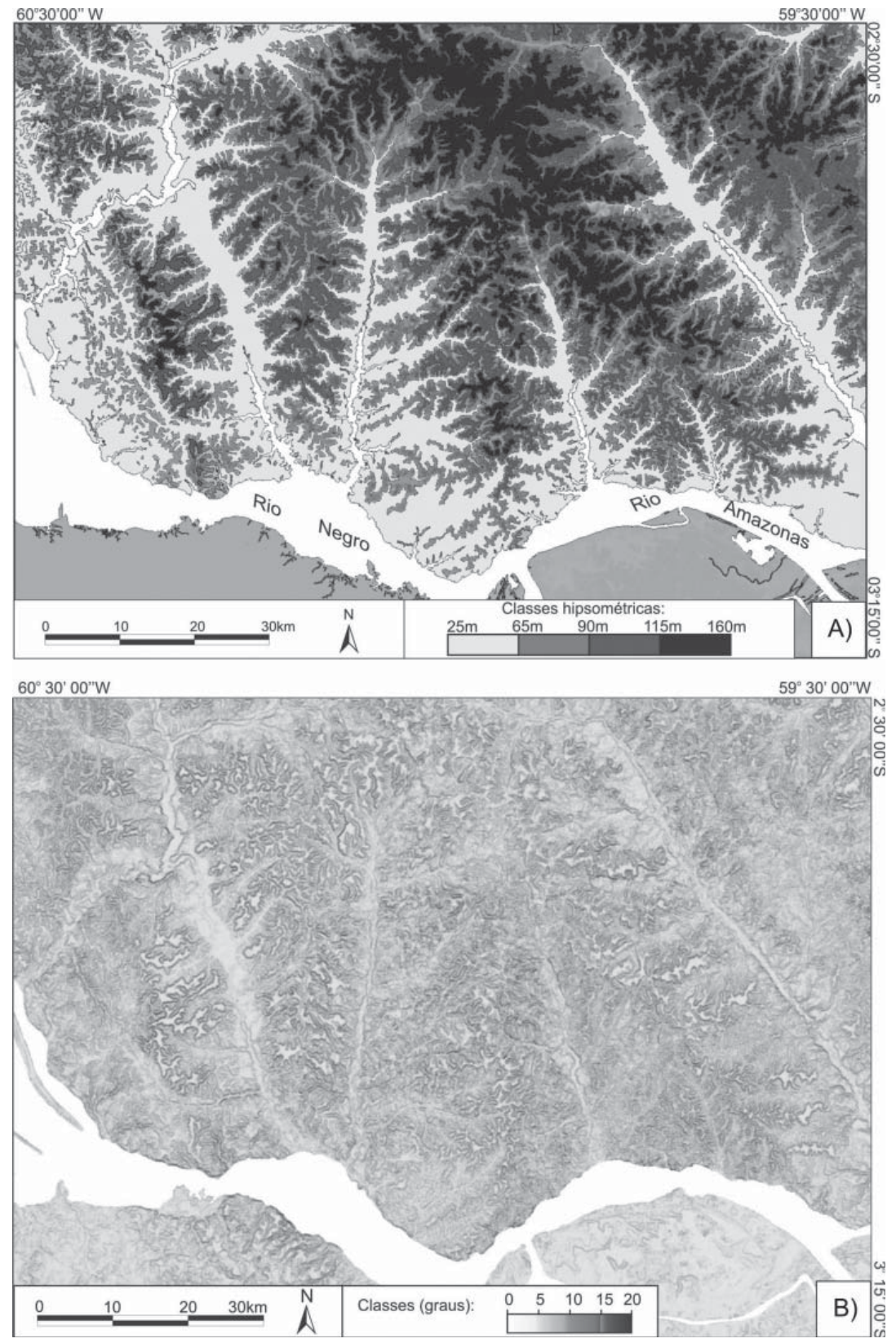

atribuído a cada classe (Fig. 3). O compartimento com altimetria entre 25 e $50 \mathrm{~m}(\Delta \mathrm{h}<50 \mathrm{~m})$ abrange os terraços fluviais, terraços erosivos e planícies de inundação. A porção entre os rios Cuieiras e Tarumã Mirim, que representa um domínio fisiográfico isolado do conjunto topográfico I (Fig. 1A), compreende desnivelamento altimétrico entre 25 e $100 \mathrm{~m}(\Delta \mathrm{h}=75 \mathrm{~m})$ e reúne feições geomórficas constituídas por interflúvios tabulares dissecados com topos mais convexizados. A região entre os rios Tarumã Mirim e Preto da Eva corresponde ao compartimento predominante da área de estudo, com desnivelamento altimétrico entre 50 e $160 \mathrm{~m}(\Delta \mathrm{h}>100 \mathrm{~m})$, composta por interflúvios tabulares com topos planos e presença de depressões.
Figura 2 - Apresentação das características do relevo da área de estudo. A) Delimitação das faixas altimétricas representativas da distribuição e organização das formas de relevo no mapa hipsométrico B) Angulos de declividades associados às feições geomórficas, no mapa de declividades. 


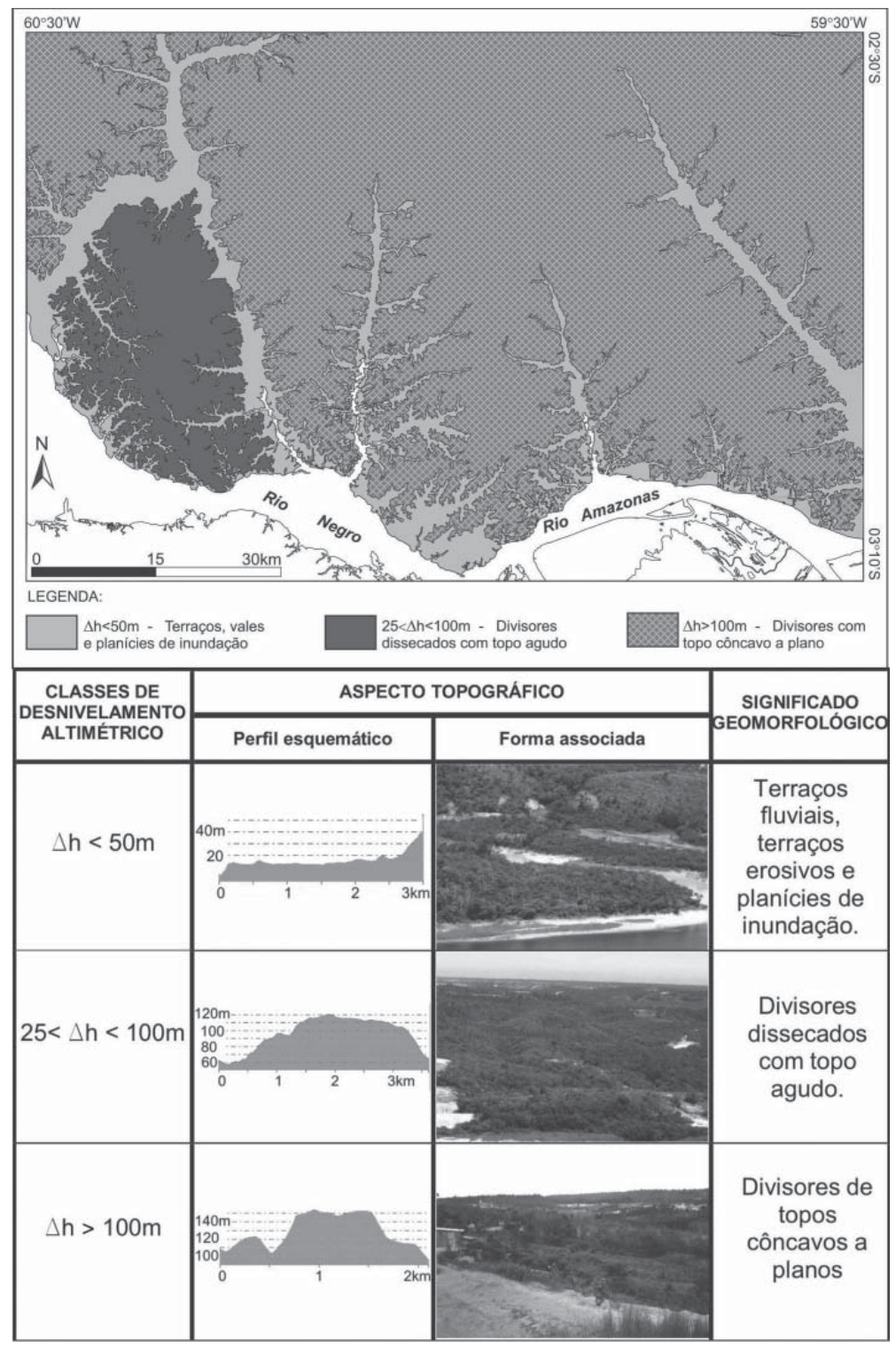

Figura 3 - Mapa de compartimentação topográfica, com delimitação de três classes de desnivelamentos. As características das classes de desnivelamento altimétricos ( $\Delta h)$, com ilustração do perfil topográfico representativo e feições geomórficas correspondentes, são apresentadas no quadro inferior.

\section{Anomalias Geomórficas Identificadas}

A paisagem da região amazônica apresenta elementos indicadores da atuação de movimentação tectônica, exemplificados por alinhamentos de feições geomórficas e elementos da rede de drenagem, tais como canais de drenagens e de desembocaduras, feições anômalas nos canais de drenagem, tais como trechos retilíneos, inflexões abruptas, desembocaduras afogadas ("rios fluviais"), capturas de drenagens, inflexões anômalas em segmentos de canais, cachoeiras condicionadas por falhas e desníveis entre margens dos canais (Sternberg, 1950; Costa et al., 1978; Forsberg et al., 2000; Costa et al., 2001; Nogueira; Sarges, 2001; Franzinelli; Igreja, 2002; Almeida-Filho;
Miranda, 2007). A distribuição espacial dos canais de drenagem mostra uma tendência de fluxo radial para o sul e elevados valores de densidade de drenagem na área com distribuição relativamente uniforme. Os valores mais elevados ocorrem ao longo das calhas coletoras principais e nas desembocaduras afogadas. Baixas concentrações de canais de drenagem são observadas nas áreas dos interflúvios de topos planos e no extremo sul da área (Fig. 4A). A análise de superfície de bases buscou definir elementos indicativos de controle tectônico paisagem, revelados por desvios abruptos, estreitamentos e distanciamentos das isolinhas (Fig. 4B). Observou-se que os alinhamentos de isolinhas NW-SE são associados principalmente com orientações de canais de drenagem, 
enquanto que na direção NE-SW apresentam correlação com alinhamentos de interflúvios. A assimetria das isolinhas está relacionada ao estilo do relevo da região, que configura um platô com dissecação nas bordas (Fig. 4B). Existe uma relação entre os canais de drenagem e a distribuição dos lineamentos na área, evidenciada principalmente pelas concentrações mais elevadas de lineamentos nas adjacências dos rios Cuieiras, Tarumã Mirim, Tarumã Açu e Puraquequara. Curiosamente, ocorre uma baixa concentração de lineamentos ao longo do rio Preto da Eva. A orientação preferencial NE está concentrada nos intervalos $35^{\circ}-55^{\circ}$, mas estão presentes expressivos lineamentos na direção N-S e na direção NW (Fig. 5A). Embora em menor quantidade, os lineamentos NW são os mais extensos da área e controlam importantes segmentos da paisagem, como os limites do compartimento topográfico com $\Delta \mathrm{h}=75 \mathrm{~m}$, bem como o alinhamento de interflúvios deste compartimento, e orientações de canais de drenagens (Fig. 5A). Em relação ao arranjo espacial, a maior concentração de lineamentos ocorre na porção entre os rios Cuieiras e Tarumã Mirim (Fig. 5B).

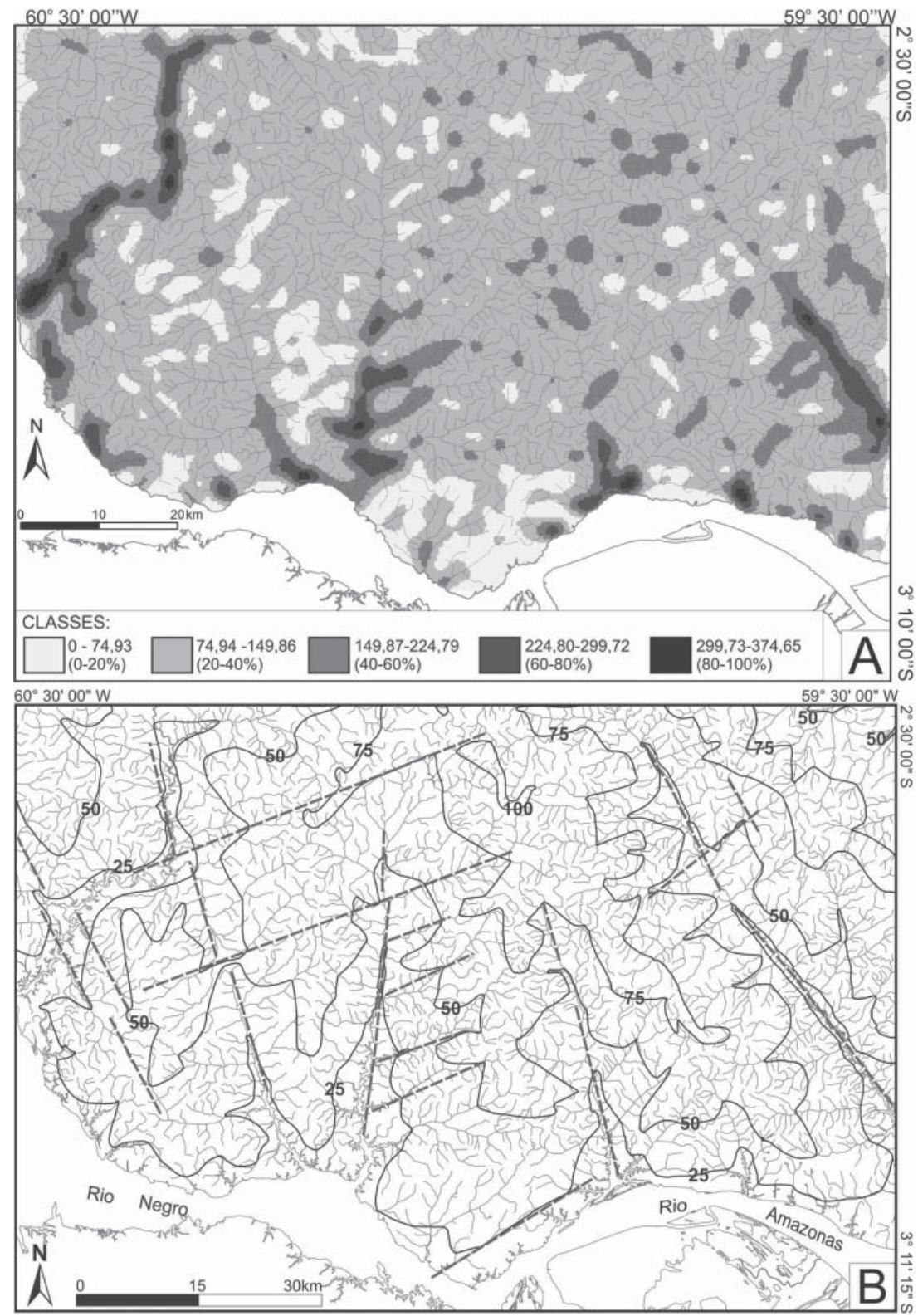

Figura 4 - A) Mapa de densidade de drenagem, mostrando as concentrações de canais de drenagem em porcentagem por $\mathrm{km}^{2}$. B) Mapa de superficie de base, com interpretação de alinhamentos associados a possiveis estruturas e comportamento das isolinhas. 

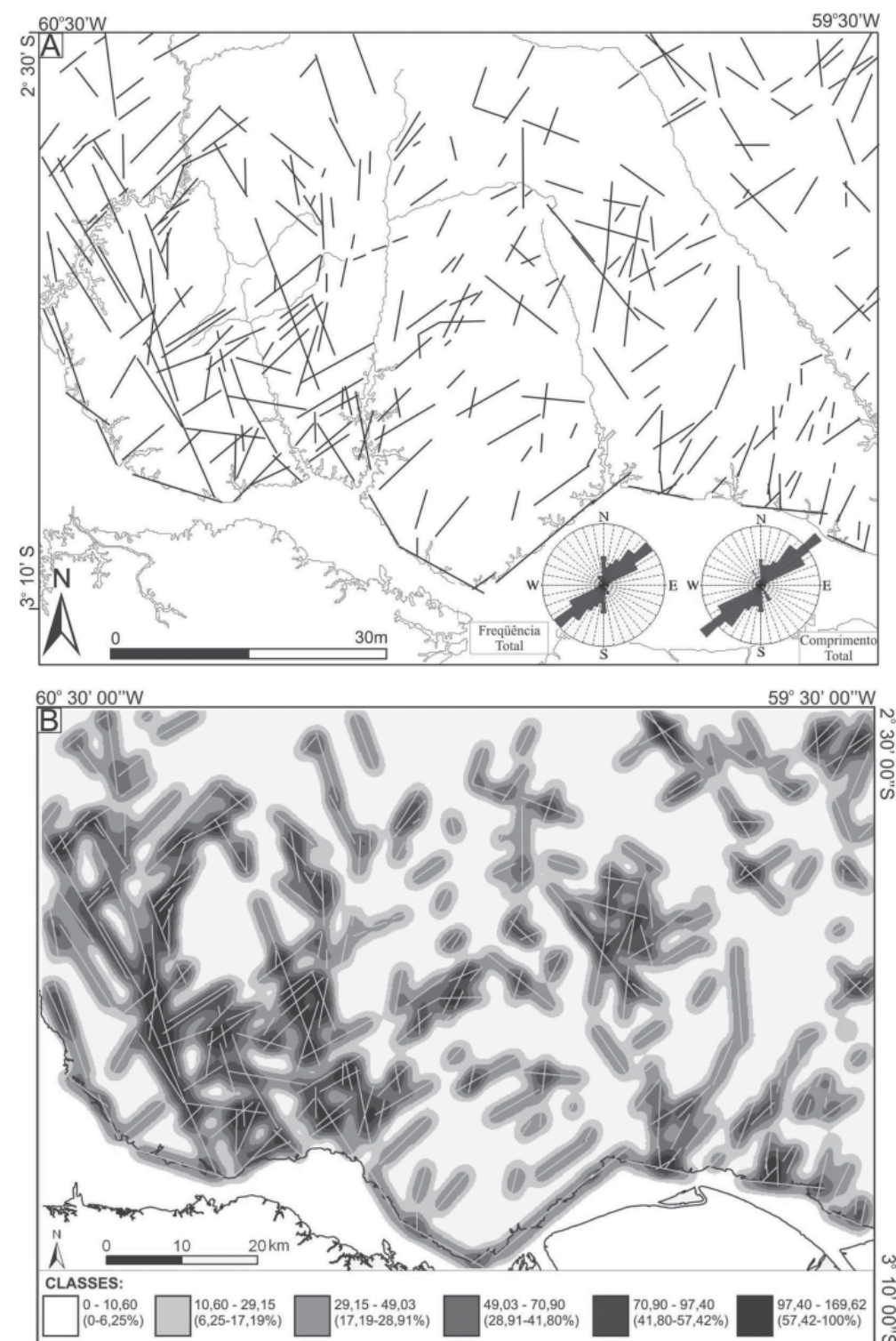

Figura 5 - A) Lineamentos interpretados a partir de imagem de relevo sombreado, com elevação de iluminação $45^{\circ}$ e azimutes $N E$ e SE, que perfazem um total de 300 lineamentos distribuidos em uma área de $7.295 \mathrm{~km}^{2}$. Os diagramas de rosetas mostram a relação da orientação dos lineamentos conforme quantidade e o comprimento total. B) Mapa de densidade de lineamentos, mostrando as áreas com concentração dos lineamentos.

\section{Conclusões Sobre a Evolução do Relevo}

A configuração do relevo da região é uma resposta às mudanças ocorridas na rede de drenagem da região amazônica, possivelmente no Paleógeno (Hoorn et al., 1995; Mapes et al., 2006), que culminou com a elaboração dos conjuntos de divisores topográficos desenvolvidos sobre as rochas sedimentares da Bacia do Amazonas (Figs. 1A e B). As análises geomorfológicas realizadas permitem sugerir que as modificações foram condicionadas à atuação de atividades tectônicas na região, sendo identificadas duas fases de reorganização da rede de drenagem na região de Manaus. Na primeira fase, marcada pela reversão do fluxo do rio Amazonas no Neomioceno em razão do soerguimento Andino (Hoorn et al., 1995; Mapes et al., 2006), os canais de drenagem da área apresentavam concordância de fluxo para sul, com a presença do interflúvio entre o rio Negro e o paleo-rio Branquinho (Fig. 6A). Uma segunda atividade tectô- nica condicionou a modificação local no sistema de drenagem, com alteração do curso do rio Cuieiras, ocorrendo aumento do comprimento de seu canal, e do rio Branquinho, que teve o canal reduzido, e geração dos igarapés Tarumã Mirim e Cachoeira (Fig. 6). Esta captura, já referida em linhas gerais em trabalhos anteriores (v.g. Costa et al., 1978; Silva; Rosseti, 2009) e delineada em termos geométricos e de processos geradores por Sarges (2008), é indicada pela inflexão anômala do rio Cuieiras de NW para SW, em um ângulo de $90^{\circ}$, como reflexo de movimentação tectônica que afetou a região, imprimiu as inflexões anômalas em trechos do canal deste rio e ocasionou a captura de drenagem da cabeceira do igarapé Tarumã Mirim (Fig. 6 C). A captura de canais de drenagem é resultante da modificação da direção do fluxo e a intercisão de canais (Deffontaines; Chorowicz, 1991), no qual o ponto onde ocorre a captura do canal é marcado por mudança brusca na direção do fluxo, frequentemente da ordem de $90^{\circ}$ (Summerfield, 1991). A origem do compartimento topo- 
gráfico $\Delta \mathrm{h}=75 \mathrm{~m}$ está relacionada à segunda fase de rearranjo da rede de drenagem, associado à formação de um bloco alto com falhas normais com mergulhos para NW e SE (Figs. 6B, C, D). Os lineamentos apresentam relação com a distribuição dos interflúvios tabulares, dissecação nas bordas dos interflúvios, limites do compartimento topográfico $\Delta \mathrm{h}=75 \mathrm{~m}$ e direção de fluxo dos rios (Figs. 2, 3 e 4). Os lineamentos NW-SE e NE-SW, que ocorrem na região do rio Cuieiras (Fig. 3), estão associados ao evento tectônico responsável pela captura de drenagem do rio Branquinho pelo rio Cuieiras. A reconstituição da paleotopografia posterior ao evento de captura de drenagem foi simulada com base nos dados de superfície de bases, pois o arranjo espacial das isolinhas revela a configuração da superfície topográfica original de uma área (Golths; Rosenthal, 1993). O relevo original de grande platô era caracterizado pela existência de duas superfícies de aplainamento, correlacionadas às superfícies $\mathrm{S} 1$ e S2 definidas por Horbe et al. (2001), cujo desenvolvimento são associados à Superfície Sul-Americana e a Superfície Velhas Inferior, respec- tivamente. Considerando a relação entre a densidade de drenagem e o padrão de distribuição das isolinhas, a região de Manaus passa por um processo de soerguimento. Segundo Jianjun et al. (1997), num estágio intermediário a tardio de um soerguimento, quando a intensidade do soerguimento é menor ou igual à taxa de incisão fluvial, uma nova formação de ravinas associadas à erosão das cabeceiras resulta em uma rede de drenagem densa, com padrão radial e implantação de canais estreitos, dando uma falsa ideia de subsidência tectônica. Os processos de denudação, que atuam no desenvolvimento da paisagem atual, promovem uma progressiva mudança da forma de relevo inicial mediante $o$ gradual rebaixamento de topos dos interflúvios e suavização da inclinação das vertentes por processos de intemperismo, erosão e movimentos gravitacionais de massa (Small, 1986), resultando na elaboração do escalonamento topográfico, num processo de dissecação regional da área, ilustrado no perfil topográfico $\mathrm{AB}$ (Figs. 1A, D), que está associado à formação da superfície S3, proposta por Horbe et al. (2001).
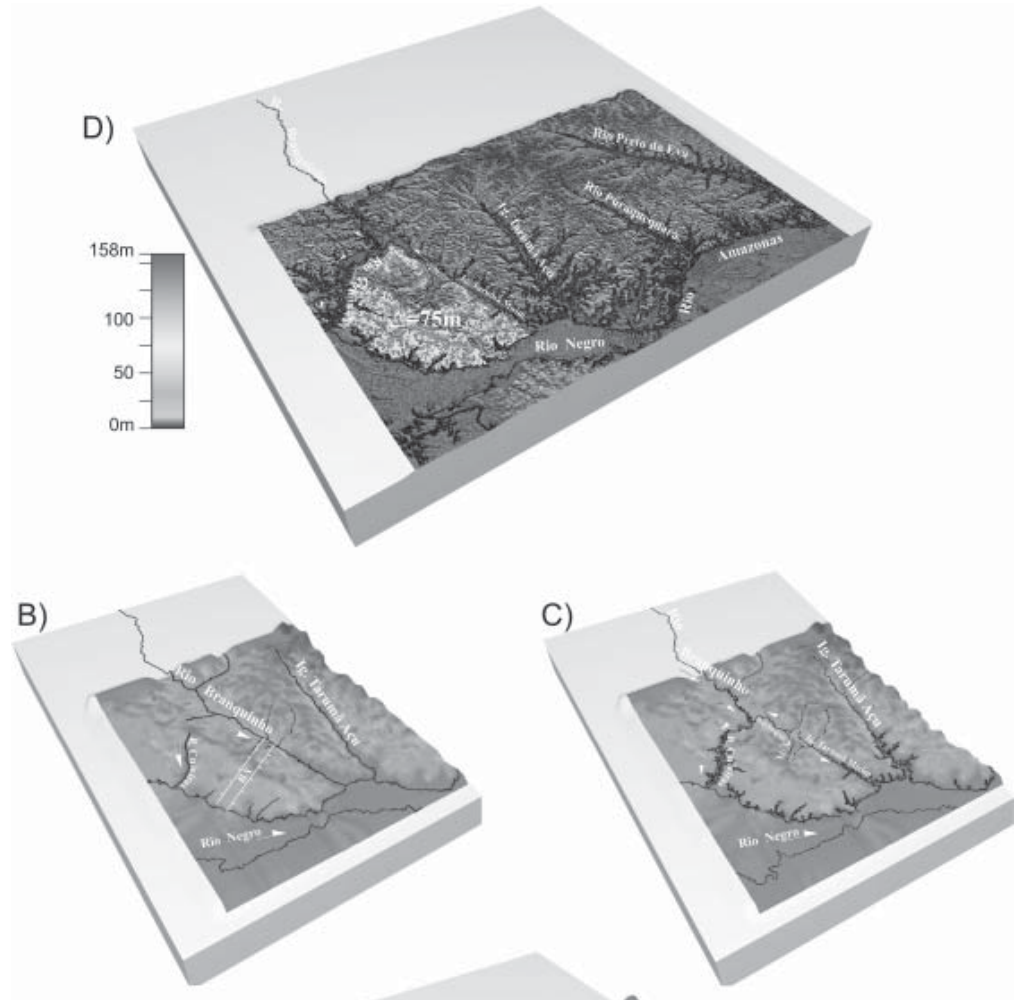

A)

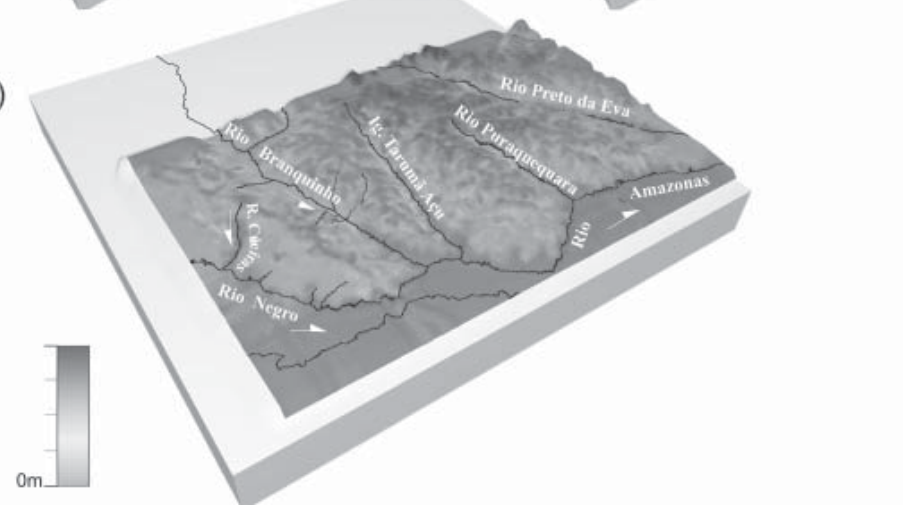

Figura 6 - Proposta para evolução da paisagem da região de Manaus, posterior a implantação dos rios Negro e Amazonas (que já fluíam para oeste e sudeste, respectivamente). A) O sistema de drenagem tinha migração preferencial para sul. Os interflúvios eram contínuos e alongados na direção $\mathrm{N}-\mathrm{S}$, apresentavam topos planos, com dissecação nas bordas em grau mais baixo que o atual. B) Uma movimentação tectônica afetou a porção sul do interflúvio dos rios Cuieiras e Branquinho e gerou um bloco alto (BA) com direção NE-SW e falhas normais com mergulhos para NE e SE (segmentos denteados). C) Captura de parte do canal do rio Branquinho pelo rio Cuieiras, em uma inflexão de $90^{\circ}$ de SE para SW. Uma parte do paleocanal do rio Branquinho foi seccionada, com a porção média tendo fluxo invertido de sul para norte, formando o igarapé Cachoeira, e a inferior dando origem ao igarapé Tarumã Mirim, mantendo a direção de fluxo para sul. A topografia apresenta um novo interflúvio, entre os rios Cuieiras, Tarumã Mirim e Negro. D) Configuração atual da paisagem da região. Os processos denudacionais foram responsáveis pela intensa dissecação das bordas dos interflúvios, que individualizaram os compartimentos $\Delta h<50 \mathrm{~m}$ e $\Delta h>100 \mathrm{~m}$. A evolução dos processos de captura de drenagem condicionou a formação do compartimento topográfico $\Delta h=75 \mathrm{~m}$ (limitado pela linha branca). As setas em branco representam o sentido fluxo dos rios. 


\section{Agradecimentos}

Os autores agradecem à FAPESP pelo suporte financeiro (Processo 02/09564-0) e pela concessão de bolsa DR a Roseane Sarges. Ao MSc. Gilberto Kaulfuss e MSc. Paulo Santos (IBGE), pelo auxílio e discussões sobre geoprocessamento e cartografia. Ao Dr. Jason Kirk, pela revisão do abstract.

\section{Referências Bibliográficas}

ALMEIDA-FILHO, R.; MIRANDA, F.P. Mega capture of the Rio Negro and formation of the Anavilhanas Archipelago, Central Amazônia, Brazil: Evidences in an SRTM digital elevation model. Remote Sensing of Environment. v. 110, p. 387-392. 2007.

BARROS, R.S. Avaliação do Modelo Digital de Elevação do SRTM na Ortorretificação de Imagens Spot 4 Estudo de Caso: Angra dos Reis - RJ. In: SIMPÓSIO BRASILEIRO DE CIÊNCIAS GEODÉSICAS E TECNOLOGIAS DA GEOINFORMAÇÃO, 1, Recife, 2004. Anais... Recife, 2004. CD-Rom.

BENTO, A.H.; FROTA, C.A. Mapeamento geotécnico da área urbana de Manaus em seu aspecto ambiental. In CONGRESSO BRASILEIRO DE GEOTECNIA AMBIENTAL, 4, Salvador, 1999. Anais... Salvador, v. 1, p. 71-77. 1999.

BEZERRA, P.E.L. Compartimentação morfotectônica do interflúvio Solimões - Negro. 2003. 194f. Dissertação (Mestrado em Geociências), Universidade Federal do Pará, Belém, 2003.

CAPUTO, M.V.; RODRIGUES, R.; VASCONCELOS, D.N.N. Nomenclatura estratigráfica da Bacia do Amazonas - Histórico e atualização. In CONGRESSO BRASILEIRO DE GEOLOGIA, 26, Belém, 1972. Anais... Belém, v. 3, p. 35-46. 1972.

COSTA, A.R.A. Tecônica Cenozóica e a Movimentação Salífera na Bacia do Amazonas e suas Relações com a Geodinâmica das Placas da América do Sul, Caribe, Cocos e Nazca. 2002. 238f. Dissertação (Mestrado em Geociências), Universidade Federal do Pará, Belém, 2002.

COSTA, J.B.S.; BEMERGUY, R.L.; HASUI, Y.; BORGES, M.S. Tectonics palaeogeography along the Amazon river. J. S. Am. Earth Sciences. v. 14, p. 335-347. 2001.

COSTA, R.C.R.; FILHO, N.T.; OLIVEIRA, A.A.B. Geomorfologia. Folha SA.20 - Manaus. In PROJETO RADAMBRASIL (Levantamento de Recursos Naturais). Rio de Janeiro: MME/DNPM. v.18, p.169-231. 1978.

CUNHA, F.M.B. Morfologia e Neotectonismo do rio Amazonas. In CONGRESSO BRASILEIRO DE GEOLOGIA, 36, Natal, 1990. Anais... Natal, v. 30, p. 193-210. 1990.

CUNHA, P.R.C.; GONZAGA, F.G.; COUTINHO, L.F.C.; FEIJÓ, F.J. Bacia do Amazonas. Bol. Geoc. Petrobrás. v. 8, p. 47-55. 1994.
DEFFONTAINES, B.; CHOROWICZ, J. Principles of drainage basin analysis from multisource data: application to the structural analysis of the Zaire Basin. Tectonophysics. v. 194, p. 237-263. 1991.

FORSBERG, B.R.; HASHIMOTO, Y.; ROSENQVIST, A.; MIRANDA, F.P. Tectonic fault control of wetland distributions in the Central Amazon revealed by JERS-1 radar imagery. Quaternary International. v. 72, p. 61-66. 2000.

FRANZINELLI, E.; IGREJA, H.L.S. Modern sedimentation in the Lower Negro River, Amazonas State, Brazil. Geomorphology. v. 44, p. 259-271. 2002.

GOLTS, S.; ROSENTHAL, E. A morphotectonic map of the northern Arava in Israel, derived from isobases lines. Geomorphology. v. 7, p. 305-315. 1993.

GROHMANN, C.H.; RICCOMINI, C.; ALVES, F.M. SRTMbased morphotectonic analysis of the Poços de Caldas Alkaline Massif, southeastern Brazil. Comput. Geosci. v. 33, p. 10-19. 2007.

HENNIG, T.A.; KRETSCH, J.L.; PESSAGNO, C.J.; SALAMONOWICZ, P.H.; STEIN, W.L. The Shuttle Radar Topography Mission. In WESTORT, C.Y. (ed). DEM 2001, LNCS 2181, Springer-Verlag. p. 65-77. 2001.

HIRUMA, S.; RICCOMINI, C. Análise morfométrica em neotectônica: o exemplo do Planalto de Campos do Jordão, SP. Rev. Inst. Geol. v. 20, p. 5-19. 1999.

HOORN, C.; GUERRERO, J.; SARMIENTO, G.; LORENTE, M. Andean tectonics as a cause for a changing drainage patterns in Miocene northern South America. Geology. v. 23, p. 237-240. 1995.

HORBE, A.M.C.; NOGUEIRA, A.C.R.; HORBE, M.A.; COSTA, M.L.; SUGUIO, K. A lateritização na gênese das superfícies de aplanamento da região de Presidente FigueiredoBalbina, nordeste do Amazonas. In REIS, J.; MONTEIRO, M.A.S. (coord). Contribuições à geologia da Amazônia. v. 2, 148-176. 2001.

HORTON, R.E. Drainage basin characteristics. Transactions American Geophysical Union. v. 13, p. 350-361. 1932.

HORTON, R.E. Erosional development of streams and their drainage basins: hydrophysical approach to quantitative morphology. GSA Bull. v. 56, p. 275-370. 1945.

HOWARD, A.D. Drainage analysis in geologic interpretation: a summation. Am. Assoc. Petrol. Geol. Bull. v. 51, p. 22462259. 1967.

JIANJUN, H.; MUKANG, H.; OLLIER, C.D. A morphometric method to determine neotectonic activy of the Wheine basin in northwerstern China. Episodes. v. 20, p. 95-99. 1997.

LATRUBESSE, E.M.; FRANZINELLI, E. The Holocene alluvial plain of the midle Amazon River, Brazil. Geomorphology. v. 44, p. 241-257. 2002. 
MAPES, R.W.; NOGUEIRA, A.C.R.; COLEMAN, D.S.; VEGA, A.M.L. Evidence for a continent scale drainage inversion in the Amazon Basin since the Late Cretaceous. In GSA PHILADELPHIAANNUAL MEETING. Disponível em http:// gsa.confex.com/gsa/2006AM/ finalprogram/abstract_113025. htm. Acessado em outubro de 2006. 2006.

MEIS, M.R.; MIRANDA, L.H.G.; FERNANDES, N.F. Desnivelamento de altitude como parâmetro para a compartimentação do relevo: bacia do médio-baixo Paraíba do Sul. In CONGRESSO BRASILEIRO DE GEOLOGIA, 32, Salvador, 1982, Anais... Salvador, v. 4, p. 1489-1509. 1982.

MEIS, M.R.M. Upper Quaternary process of the middle Amazon area. GSA Bull. v. 82, p. 1073-1078. 1971.

NOGUEIRA, A.C.R.; SARGES, R.R. Characterization and genesis of waterfalls of the Presidente Figueiredo region, Northeast State of Amazonas, Brazil. An. Acad. Bras. Ciênc. v. 73, p. 287-301. 2001.

NOGUEIRA, A.C.R.; HORBE, A.M.C.; PAZ, J.D.S.; MOTTA, M.B.; ROZO, J.M.G. O Neógeno da Amazônia Ocidental. In SIMPÓSIO DE GEOLOGIA DA AMAZÔNIA, 9, Belém, Anais... Belém, 2006. CD-Rom.

NOGUEIRA, A.C.R.; VIEIRA, L.C.; SUGUIO, K. Paleossolos da Formação Alter do Chão, Cretáceo-Terciário da Bacia do Amazonas, regiões de Presidente Figueiredo e Manaus. In SIMPÓSIO SOBRE O CRETÁCEO DO BRASIL, 5, Serra Negra, Resumos... Serra Negra, v. 1, p. 261-266. 1999.

ROZO, J.M.G.; NOGUEIRA, A.C.R.; HORBE, A.M.C.; CARVALHO, A.S. Depósitos Neógenos da Bacia do Amazonas. In REIS, J.; MONTEIRO, M.A.S. (coord). Contribuições à geologia da Amazônia. v. 4, p. 116-123. 2005.

SANTOS, P.R.A.; GABOARDI, C.; OLIVEIRA, L.C. Avaliação da precisão vertical dos modelos SRTM para a Amazônia. In SIMPÓSIO BRASILEIRO DE SENSORIAMENTO REMOTO, 12, Goiânia, Anais... Goiânia, p. 4473-4480. 2005.

SARGES, R.R. Relações entre as estruturas tectônicas, sedimentação coluvial e geomorfogênese da região de Manaus, Amazonas. 2008. 109f. Tese (Doutorado em Geociências), Universidade de São Paulo, São Paulo, 2008.
SILVA, C.L.; ROSSETTI, D.F. História geológica dos rios da Amazônia. Cienc. Cult., v. 61, n. 3, p. 24-26. 2009. Disponível em: <http://cienciaecultura.bvs.br/scielo.php?script=sci_ arttext\&pid=S0009-67252009000300010\&lng=pt\&nrm=iso $>$. Acesso em: 10 jan. 2011.

SILVA, T.M. A Estruturação Geomorfológica do Planalto Atlântico no Estado do Rio de Janeiro. 2002. 265f. Tese (Doutorado em Geografia), Universidade Federal do Rio de Janeiro, Rio de Janeiro, 2002.

SILVA, T.M.; PEIXOTO, M.N.O.; MOURA, J.R.S. Relief compartiments and distribuition of Quaternary depositional features in the Brazilian Southeastern Plateau. The European Geographer. v. 9, p. 172-181. 1995.

SMALL R.J. The study of landforms: a textbook of Geomorphology. New York, University Cambridge Press. $2^{\mathrm{a}}$ ed. 1986. 495p.

STERNBERG H.O. Vales tectônicos na planície amazônica? Rev. Bras. Geogr. v. 12, p. 3-26. 1950.

STRAHLER, A.N. Hypsometric (area-atitude) analysis of erosional topography. GSA Bull. v. 63, p. 1117-1142. 1952.

SUMMERFIELD, M.A. Global Geomorphology: An introduction to the study of landforms. New York, Longman Scientific e Technical. 1991. 537p.

TRICART, J. Aperçu sur le Quaternaire Amazonien. Annais de Geographie. v. 473, p. 1-54. 1977.

USGS. DEM 3". Disponível em http://seamless.usgs.gov. Acessado em setembro de 2003. 2003.

VALERIANO, M.M. Modelo Digital de Elevação com dados STRM disponíveis para a América do Sul. Relatório INPE10550-RPQ/756, INPE, São José dos Campos, 71p. 2004.

VALERIANO, M.M.; KUPLICH, T.M.; STORINO, M.; AMARAL, B.D.; MENDES JR. J.N.; LIMA, D.J. Modeling small watersheds in Brazilian Amazonia with Shuttle Radar Topographic Mission-90m data. Comput. Geosci. v. 32, p. 1169-1181. 2006. 